Anales de Literatura Hispanoamericana ISSN: 0210-4547

http://dx.doi.org/10.5209/ALHI.58815

\title{
Libertades subterráneas: rastros y herencias en El túnel y The Collector
}

\author{
Álvaro Arango Vallejo ${ }^{1}$ y Manuel Botero Camacho
}

Resumen. El propósito de este artículo es establecer las posibles conexiones literarias y filosóficas entre El túnel de Ernesto Sábato (1948) y The Collector de John Fowles (1963). Para lograr esto se estudiarán motivos y situaciones comunes en ambas novelas a través del marco filosófico del existencialismo de Jean Paul Sartre. Los puntos principales que se consideran serán las visiones sartrianas de libertad, amor y poder. Para lograr un concepto más o menos claro de dichas ideas, se tendrán en cuenta obras tanto filosóficas como literarias del intelectual francés, y se procederá a investigar hasta qué punto la influencia de Sartre se presenta evidentemente en las novelas objeto de este estudio, ya sea a través de referencias directas al filósofo, o a leitmotifs recurrentes en las obras.

Palabras clave: Sartre; Sábato; Fowles; existencialismo; mala fe; libertad.

\section{[en] Subterranean freedoms: heritage and traces in El túnel and The Collector}

\begin{abstract}
The purpose of this article is to establish the possible literary and philosophical connections between El túnel (1948), written by Ernesto Sábato and The Collector (1963) by John Fowles. In order to accomplish this, motifs and common situations in both novels will be studied with an existentialist philosophical framework, based on the works of Jean Paul Sartre. The main points considered will be the sartrean visions of freedom, love and power. For a more or less clear concept of these ideas, both philosophical and literary works by the French intellectual will be taken into account. The investigation will analyze to what extent the influence of Sartre can be traced in the novels subject to this study, either through direct reference to the philosopher, or through similar recurring leitmotifs.
\end{abstract}

Keywords: Sartre; Sábato; Fowles; existentialism; bad faith; freedom.

Sumario. 1. A manera de introducción. 2. Del engaño al auto-engaño. 3. El túnel filosófico. 4. El mal como ascensión intelectual.5. Soy mirado luego existo. 6. Las libertades subterráneas.

Cómo citar: Arango Vallejo, A. y Botero Camacho, M. (2017) Libertades subterráneas: rastros y herencias en El túnel y The Collector, en Anales de Literatura Hispanoamericana 46, 407-428.

1 Rheinische Friedrich-Wilhelms-Universität Bonn, Alemania.

E-mail: s3alaran@uni-bonn.de

2 Universidad Complutense de Madrid, España.

E-mail: mbotero@ucm.es 


\section{A manera de introducción}

El propósito de este artículo es establecer las posibles conexiones literarias y filosóficas entre El túnel de Ernesto Sábato (publicada en 1948) y The Collector de John Fowles (publicada en 1963). Para lograr esto se estudiarán motivos y situaciones comunes en ambas novelas a través del marco filosófico del existencialismo de Jean Paul Sartre. Los puntos principales que se consideran serán las visiones sartrianas de libertad, amor y poder. Para lograr un concepto más o menos claro de dichas ideas, se tendrán en cuenta obras tanto filosóficas como literarias del intelectual francés, y se procederá a investigar hasta qué punto la influencia de Sartre se presenta evidentemente en las novelas objeto de este estudio, ya sea a través de referencias directas al filósofo, o a leitmotifs recurrentes en las obras.

Las relaciones entre los autores aquí estudiados y el existencialismo ya han sido exploradas individualmente. El caso de Sábato es, seguramente, más notorio que el de Fowles: el argentino es considerado actualmente el autor latinoamericano existencialista por excelencia, y no es difícil encontrar el discurso sartriano en un análisis de su obra: "La Nada, tema central de la producción literaria del escritor argentino, así como los fenómenos que la acompañan a manifestarse, nos determinan relacionar su pensamiento a la posición fundamental de la filosofía existencialista" (Petrea 1986:21).

Por otra parte, en el ámbito de las letras inglesas, la crítica parece estar de acuerdo en afirmar que, aunque Fowles no abraza el existencialismo plenamente, sus obras contienen un matiz de dicha filosofía muy evidente para ser ignorado: "Although he [Fowles] firmly rejects existentialism's nausea he espouses something of its positive committed literary stands; and his plots are fraught with choice, his characters existentially aware" (Huffaker 1980: 24). El mismo Fowles reconoce una influencia tanto de Sartre como de Camus en lo que el describe como el "clima" de sus obras (Huffaker 1980: 87). Sin embargo, Fowles sigue siendo una figura enigmática para la crítica: "He [Fowles] is a paradoxical figure: a didactic and coercive libertarian; an evolutionary socialist profoundly committed to the values of a Romantic individualism, which his existentialism is called upon to validate" (Conradi 1982: 16).

Las aproximaciones existencialistas a su obra se han concentrado especialmente es sus novelas más experimentales y voluminosas como The Magus (1965) o The French Lieutenant's Woman (1969).

Sin embargo, las intenciones de este artículo van un poco más allá de enumerar conexiones que se han realizado previamente. El propósito de estas páginas es describir una especie de triángulo interpretativo, posibilitado por la obra de Sartre, donde el análisis independiente de cada uno de las novelas estudiadas enriquece potencialmente al de la otra:

Normalmente se acepta la idea de que si el documento B se ha producido antes que el documento $\mathrm{C}$, que es análogo al primero en términos de contenido $\mathrm{y}$ estilo, resulta correcto suponer que el primero ha influido en la producción del segundo y no al revés. Se podría a lo sumo formular la hipótesis de un documento arquetipo A, producido antes que los otros dos, a partir del cual los 
dos posteriores se derivaran de modo independiente. Esta hipótesis de un texto arquetipo puede ser útil para explicar analogías entre dos textos conocidos que de otro modo serían inexplicables: pero es necesaria solo si las analogías (los indicios) no pueden explicarse de otro modo más económico (Eco 1992: 59, 60).

No se intentará negar ningún tipo de influencia directa, en realidad toda referencia contribuirá al análisis realizado. No obstante, el vínculo que se propone es más intangible. Por ejemplo, hay quienes reportan de forma específica (Olshen 1978; Conradi 1982) sobre las fuentes de inspiración directas de The Collector, dejando claro que el existencialismo no fue el propulsor directo de la obra.

He came upon the idea for the novel first from viewing a performance of Bartok's opera, Bluebeard's Castle, in which he was particularly impressed by the symbolism of the man imprisoning women underground; and then, about a year later, from an actual incident reported in the newspapers of a London boy who captured a girl and imprisoned her in an air-raid shelter for over three months before her eventual rescue (Olshen 1978: 15-16).

Estas páginas no desean afirmar que sea indispensable leer a Sábato, o a Sartre en ese caso, para que Fowles sea inteligible, pero sí es necesario mencionar aquellos caudales de los que es posible que hayan bebido consciente o inconscientemente. Conceptos como la libertad, el masoquismo, el solipsismo, e incluso la mala fe están presentes de tal modo que justifican el atrevimiento de establecerlo como un sustrato familiar a los dos autores. Tampoco será una prioridad establecer si Sábato leyó a Sartre, si Fowles leyó a Sartre, o si Fowles leyó a Sábato. Sea intencional o accidentalmente, los vínculos temáticos entre los tres factores aquí estudiados parecen evidentes. En las páginas sucesivas se intentará ponerlos en evidencia de forma comprensible.

\section{Del engaño al auto-engaño}

El futuro ha echado raíces en el presente. Merlín, Excalibur.

If you choose not to decide you still have made a choice. Rush, Freewill.

A lo largo de estas breves líneas se busca analizar el ejemplo que para ilustrar la mala fe utiliza Jean Paul Sartre. El ejemplo se encuentra en la parte segunda del capítulo segundo de El ser y la nada. (Sartre 1998: 100). La intención de este ejercicio es llegar a una mejor comprensión del concepto de la mala fe y la forma como esta se expresa o se comporta, como se da; cómo, en última instancia, puede ser diferenciado de la mentira.

En la parte primera del capítulo acerca de la mala fe se expone la mentira como una actitud negativa que adopta una persona, a quien se le llamará mentiroso, frente a una verdad. Esto es, el mentiroso tiene plena conciencia de la verdad que oculta. Esta conducta incluye a otro, aquel quien es engañado. El mentiroso intenta 
engañar a otro, pero al conocer la verdad no puede engañarse a sí mismo. La mala $\mathrm{fe}$, que es una forma particular de auto-engaño, tiene la misma estructura de la mentira, con la única diferencia de que el mentiroso y el engañado son el mismo sujeto. Este enmascaramiento de la verdad, al punto de que el sujeto puede perder de vista la verdad y, por lo tanto creer su propia mentira, es lo que se ha denominado la mala fe.

En la primera parte del ejemplo que ilustra la conducta que nos ocupa, se presenta a una mujer que, estando al corriente de las intenciones de su pareja, se enfrenta con un dilema: es la primera cita; ella sabe que las palabras dulces de su interlocutor tienen una intención, una intención que se proyecta al futuro. Las conductas del hombre están basadas en el deseo, hecho que no desconoce la mujer $\mathrm{y}$, por lo tanto esperan la satisfacción de este.

La mujer se encuentra a gusto en ese presente, un presente llano que no le exige una decisión con respecto a la evolución de su cita. El momento es agradable, el hombre la halaga. En una frase que contiene en sí misma tanto de respeto como de deseo, tal podría ser: "Tengo tanta admiración por usted..." (Sartre 1998: 100) la mujer entiende lo que de absoluto y puro presente contiene la frase, la desnuda de intencionalidad, le niega su futuro. ¿Por qué? Porque le sirve así, porque de lo contrario debe optar por una posición, si acepta la frase cargada del contenido sexual que lleva consigo, debe decidir con respecto del futuro, esto es, una vez entendida la intención de la frase debe escoger si detiene los posibles que le esperan, o si los permite. Sin embargo, la interpretación inmediata de la frase, el presente puro, no le exige ninguna decisión, puede así retardar el momento de escoger escudada en lo que de respetuosas tienen las palabras de su pareja.

La mujer se enfrenta a un dilema, como se ha visto, las palabras del hombre acarrean un contenido sexual pero están encadenadas de tal forma que también están cargadas de respeto y mesura. La mujer entonces piensa, y este es un punto muy interesante, piensa por el otro, piensa en su propia reacción ante las posibles intenciones de su pareja. Es un poco confuso pero el análisis de la situación que hace la mujer, lo hace a partir de suposiciones. a) Si el hombre tan solo la desea, se horroriza. b) Si el hombre no la desea pierde el encanto. ¿Qué quiere la mujer? Hay que tener en cuenta que todo esto ocurre de manera simultánea al discurso del hombre, se da mientras que el hombre sigue hablando. Lo contradictorio recae en que es ella quien quiere perpetuar ese presente agradable en el cual no tiene que decidir y, no obstante, ya se está planteando las decisiones posibles, dejarse desear o no, dejarse respetar o no. Finalmente ella sabe lo que quiere, quiere que el sentimiento se dirija a ella como persona, a su libertad, que se dirija a ella en tanto espíritu y en tanto cuerpo. Que el hombre la desee y que desee también su libertad.

El hombre le coge la mano, y toda la especulación de la mujer encaminada a retardar la decisión se ve truncada. Tiene que tomar la decisión ahora. En este punto existen al menos cuatro actitudes que la mujer puede adoptar: a) Puede retirar la mano, romper el momento en el que se encontraba tan a gusto, diciéndose a sí misma que no tolerará ser solo deseada; b) Puede retirar la mano, porque verdaderamente no quiere ser tan solo deseada; c) Puede dejar la mano y conservar la armonía del momento, incómoda por ser deseada; d) Puede dejar la mano queriendo ser deseada. 
Las posibilidades a) y b), y las posibilidades c) y d), difieren únicamente en el que la primera y la tercera son engaños, y en que la segunda y la cuarta responden a decisiones basadas en un sentimiento verdadero. Esto es, a) y c) son mentiras, pues ella conoce la verdad, en tanto que las restantes son verdaderas pues no hay engaño de por medio. Sin embargo, la mujer escoge una quinta posibilidad, una posibilidad que se asemeja en estructura a la actitud que asumió cuando desprendió del trasfondo sexual la frase de su pareja, que es no tomar una decisión, es abandonar la mano sin percibir que lo hace, esto es, dirige al interlocutor y a su discurso a estados más elevados que los del cuerpo, es puro espíritu, la mano entonces no hace parte del momento, la desprende por completo de la conversación y de la intención de su pareja, (para ella), niega la mano y las implicaciones sexuales que abandonar la mano conllevan.

La mujer ha adoptado una conducta de mala fe, puesto que no ha tomado una decisión al estilo de las cuatro posibilidades, ha decidido no decidir en un momento en el cual depende de ella acceder o negarse al flirt. Pero ella no ve sino el retraso de la decisión, en eso consiste su auto-engaño, una vez más, a retrasado el momento de tomar la decisión, no obstante, ha tomado una decisión así ella no lo quiera, ha decidido no decidir, como el hombre que se encuentra ante la figura autoritaria en el cuento de Kafka titulado "Ante la Ley". Escoger no decidir es haber decidido, y de esta manera al ser la conducta de mala fe fundamento de las decisiones, y consecuencias, subsiguientes, que van a determinar el futuro, se puede decir, que el futuro ha echado raices en el presente.

\section{El túnel filosófico}

La diferencia entre la literatura y la filosofía es que los escritores saben que están diciendo mentiras por el contrario los filósofos creen que está diciendo la verdad.

A lo largo de este apartado, se propone una lectura de El túnel (Sábato 1983) a la luz de la filosofía de Sartre. Este apartado no tiene en absoluto la pretensión de ser una teoría apodíctica, ni un dogma que cierre cualquier otra interpretación de lo poético o literario en la novela. No es más que un conjunto de intuiciones sobre lo que podría no ser accidental dentro del texto; es la memoria del Sartre de "El existencialismo es un humanismo" (Sartre 1999), es una memoria de las lecturas de Borges, en quien es frecuente encontrar juegos filosóficos, en última instancia, teniendo en cuenta que la literatura es un juego de reconstrucción, podría ser que $E l$ túnel sea la escritura de algo que tiene aspiraciones bastante más elevadas.

Locke intentó inventar o, por lo menos, lo soñó, un lenguaje de particulares. Un lenguaje en donde no existieran universales, ya que estos se prestan para ambigüedades. Él estaba haciendo filosofía y notaba que el lenguaje lo limitaba. Quiso, entonces, proponer uno que no fuera tan limitante, ni tan limitado. Si cada cosa tiene su nombre, entonces el hombre sabría exactamente a qué se está refiriendo cada palabra y así no habría dudas acerca de los significados ${ }^{3}$ (Locke

3 Es imposible no percibir en el afán de Locke una evocación clara al Cratilo de Platón. 
1956: 391). El objetivo principal del lenguaje es el de representar la realidad, entonces Locke decide que la manera como más acertadamente se puede representar la realidad, es nombrando cada cosa particularmente.

Dos objeciones inmediatas saltan a la vista. La primera es que asignar a cada objeto particular su propio nombre equivaldría a tener el mismo número palabras que número de objetos; la ironía de Swift, de alguna forma prefigura esta objeción. Es muy posible que Swift estuviera familiarizado con las teorías de Locke, también cabe entretener la posibilidad de que esta misma parodia, y las otras que los viajes de Gulliver aportan, hayan surgido como objeciones a este tipo de especulaciones acerca del lenguaje.

La segunda es que existe una dislocación de lenguaje y de la lógica. Magritte, al escribir en una de sus obras la frase "esto no es una pipa" está evidenciando la fractura del lenguaje separando el objeto, su nombre, su función y su interpretación. Lewis Carroll pondrá en labios de Alicia la frase "I can see nobody on the road", frase que no hace esperar una respuesta: "increíble, ser capaz de ver a nadie y a tanta distancia". La imposible conversación con Funes, hace del narrador un mentiroso cuando el lector atiende a las implicaciones de un lenguaje de particulares. Swift había representado el trabajo que esto requería al cargar a dos interlocutores con sacos llenos de objetos para que pudieran comunicarse. Esas fallas del lenguaje y de la lógica deben ser restituidas, pero el relato fantástico no lo hace, el lector, que se ha convertido en personaje, debe aportar esa conexión. Dentro del mismo orden de ideas vale mencionar la situación que Borges presenta en "La casa de Asterión" en la que el minotauro confiesa su ignorancia de la letra escrita (Borges 1957: 68).

Estos relatos evidencian un gran problema al que se enfrenta la filosofía, un gran problema del género humano: el problema del lenguaje. Estos ejemplos muestran cómo el lenguaje se vuelca sobre sí mismo y surgen múltiples interrogantes; pero el interés aquí recae sobre uno específicamente: ¿será que lo que se entiende al leer unas líneas, es lo que escritor de dichas líneas quería decir? Una variante, más sutil y, acaso, más interesante, se aprecia en El túnel, novela en la que el escritor es un pintor. ¿Por qué podría parecer tan curioso que sea un pintor quien escribió el relato? En esta pregunta está contenido el problema del lenguaje que sufre Juan Pablo Castel a lo largo de su túnel, en esa pregunta está cifrada la angustia que padece Castel. La pintura es un arte en el cual se plasma la recreación del mundo en dos dimensiones, se puede percibir de manera espacial y, en ella, el pintor expresa el mundo como lo ve. Muy al contrario la escritura es lineal y, por lo tanto, temporal. Para describir una imagen instantánea tiene que recurrir a rodeos y explicaciones. Para describir un pensamiento, una confusión, incluso el flujo de conciencia, necesita, además de espacio, tiempo. Esa limitación alteraba Castel. En realidad el lector no puede estar seguro de la veracidad de su relato puesto que él procura explicar los hechos de la misma forma como hubiera pintado un cuadro, teniendo en cuenta, incluso, la mezcla de los colores. Todo desde su punto de vista, subjetivo, artístico, creador y alucinante; poético y terrible.

COSAS todas conocidas por el pintor en el instante mismo de su rapto, pero de las cuales debe hacer abstracción para restituir con un solo rasgo, sobre la lámina de su tela, la suma auténtica de un aleve pinta de color. 
Pinta estampada como un sello, sin ser no obstante cifra ni sello, sin ser signo ni símbolo, sino la cosa misma en su hecho y su fatalidad - cosa viva, en todo caso, y asida en lo vivo de su natal tejido: injerto más que extracto, síntesis más que elipsis.

Así, de un "territorio" más vasto que el del pájaro, el pintor sustrae, por desgarramiento o por lento apartamiento, hasta plena apropiación, ese puro fragmento de espacio hecho materia, cosa táctil, y cuya demacración suprema se hace la tarea insular del pájaro sobre la retina humana (Perse 1985: 17).

La sobrecogedora descripción que hacen Perse del hermosísimo oficio del pintor, que presa de un arrebatamiento casi místico, transforma el mundo en poesía visual, parece suficiente para contestar a la pregunta acerca del error categorial que sugiere el hecho de que Castel cuente una historia. ¿Cómo puede pedírsele a un pintor que se comunique con los hombres de otra forma?

A Juan Pablo Castel, se le percibe a lo largo de la novela como un hombre angustiado profundamente, necesitado de María y con un terrible problema de comunicación. Es un hombre que decide matar una mujer y que lo hace con plena conciencia de ello. Es posible, y sin que esto sea hilar muy finamente, es lo que podría calificarse con el adjetivo de existencialista. Más aún, Juan Pablo es el existencialista por antonomasia. Para justificar esta afirmación se recurrirá a los pilares básicos de la doctrina existencialista según aparecen en el artículo de Sartre titulado "El existencialismo es un humanismo" (Sartre 1999).

La libertad, de acuerdo con Sartre, consiste en una capacidad de elección que compromete a toda la humanidad. Esto es, que en la medida en que yo ejecute o lleve a acabo los actos que construyen mi vida también estoy construyendo la vida de los demás. Incluso estoy construyendo el mundo, dado que el hombre no es definible sino hasta su realización, hasta que se elija por medio de actos. La vida se construye mediante los actos, con hechos, con movimiento: es una vida fenomenológica. Cuando yo hago algo inmediatamente estoy dejando de hacer otra cosa. Cuando yo afirmo algo estoy negando todo lo demás. Castel necesitaba que María le afirmara su amor ya que, con esta afirmación, estaba negando a todos los demás. Cuando yo hago algo lo hago porque creo que está bien, de no ser así estaría actuando de mala fe. Con mi acto, además, estoy comprometiendo a toda la humanidad. La angustia viene al hombre por su condición de desprotegido, es una angustia de su propia libertad. Al no haber un Dios, o un destino, o pre-destino, entonces no hay a quien culpar de nuestros actos, ni de sus consecuencias, somos responsables por el mundo. Se necesita también del otro para la realización del individuo, ya que en un mundo de "A", la "A" no se reconoce a sí misma porque necesita de otro, distinto, que le reconozca, le comprometa, le defina por medio de actos.

Sábato está frente al reto y acepta el desafío de hacer una novela metafísica y existencialista donde el centro de ella es el hombre con sus problemas extremos, últimos: la angustia, el deseo de poder, la perplejidad, el temor ante la muerte, el anhelo de absoluto y de eternidad, la rebeldía ante lo absurdo de la existencia, la soledad, la incomunicación, en fin el dolor de vivir y la búsqueda afanosa de esperanzas e ilusiones que le impidan sucumbir ante la desilusión y el desengaño (Boscán de Lombardi 1978: 21). 
Entonces Castel aparece como un sujeto angustiado, necesitado: un existencialista. El juego de relaciones puede llevarse aún más lejos. Castel es argentino por lo tanto no tendría sentido que se llamara Jean Paul, pero Juan Pablo tiene sentido. Es necesario hilar delgado. Sartre desarrolla una reescritura de $L a$ Orestiada (Esquilo 1980). En esta tragedia griega Orestes se convierte matricida tras vengar la muerte de su padre. Sartre entonces, basado en esta pieza de teatro, escribe Las moscas en donde traslada la historia del matricidio al siglo XX. Habrá que dar sentido a la relación entre Las moscas y El túnel. Para dar coherencia a esta relación el lector habrá de remitirse a imágenes del texto que aparecen como guiños del autor a lo largo de la novela.

De acuerdo con el psicoanálisis, aquel túnel con una luz al final que dicen haber visto aquellos que han estado al borde de la muerte o incluso aquellos que dicen haber muerto y, sin embargo, están aquí, no es una visión del otro mundo sino todo lo contrario: es una visión de este mundo, puesto que es el recuerdo de la primera experiencia traumática del hombre: el parto. Ese túnel no es otro que el que separa al útero del mundo. Acaso será de ese túnel al que se refiere Sábato. No parece ser accidental que la mujer que tanto conmueve a Juan Pablo se llame María, que hereda el nombre de la madre por excelencia cultura occidental. ¿Qué otro nombre le pondría el lector a quién va a representar la madurez, la vida, la redención, la madre? El cuadro que conforma el único vínculo entre Castel y María se llama "Maternidad". Es un cuadro que en primer plano tiene una mujer que mira un niño jugando. Además, tiene una ventanita por donde se observa una mujer que mira el mar con aire de desolación y de profundo dolor. Es posible que esté describiendo el desamparo que sugiere la expulsión del vientre. La nostalgia podría ser por el mar (origen). Por último Castel asesina a María y la tesis que aquí se defiende es que $E l$ túnel es una reescritura de Las moscas. Es posible, entonces, que Castel estuviera matando a su madre.

El autor deja unas pistas más evidentes que otras y, ya que se trata de desvelar la novela, se presentarán en forma de dos conjeturas. Una es tratar a mostrar cómo el autor explica al lector su intención de reescribir la filosofía de Sartre. La segunda trata de arrojar alguna luz sobre el misterio de las últimas palabras que Allende le grita a Castel. Para la primera será necesario remitirse al episodio de la novela en cual Hunter habla acerca de la novela policiaca, proponiendo una trama en la que la familia de un hombre ha sido víctima de un asesino que perpetró los crímenes en algún tipo de orden lógico. El hombre, ante la incompetencia de la autoridad, decide investigar por su cuenta descubriendo el patrón que rigen los asesinatos. Por último, el hombre pronostica, confiado, en dónde se cometerá el siguiente crimen pero, una vez allí, a la hora correcta y demás, no ve al asesino. Entonces, comprende con horror, que el asesino es él y termina por suicidarse. Hunter está contando, a grandes rasgos, el cuento de Borges titulado "La muerte y la brújula" (Borges 1996), cuento en el cual un detective llamado Lönnrot descubre la participación de Red Scharlach en los asesinatos que investiga, pero no puede impedir que el último, el suyo, se cometa. Red Scharlach es una traducción libre al inglés de Rojo Escarlata, Lönnrot, la traducción libre al alemán de El hombre rojo. $\mathrm{Y}$ aunque la pista alude al uso de los nombres trucados, no se agota allí. En el cuento, la clave decisiva para la resolución del enigma viene en una carta firmada 
por un Baruj Spinoza y, entre otras teorías, hay una que defiende que el cuento es una reescritura de la filosofía de Spinoza.

Para dar cuenta de la segunda conjetura, se propone una interpretación de la palabra insensato, proferida con encarnizamiento por Allende al enterarse de que Castel había matado a María. Para tal efecto es menester recordar el sueño con el cual Sábato hace un guiño a Kafka: el sueño de la metamorfosis. Castel sueña que un mago con ojos prodigiosos lo convierte en pájaro y que no puede comunicarse con sus amigos, en efecto, estos ni siquiera notan lo que le está sucediendo. Bien, es posible que el mago fuera el ciego Allende; no es del todo claro el porqué, pero el hecho de que el nombre tenga significado en sí mismo y la específica mención a los ojos; en cualquier caso la metamorfosis cobra algún sentido cuando se recuerdan, después de que suceden, los hechos que van a concluir con el encierro de Castel. Cuando a Castel lo convierte el mago en un pájaro, le está otorgando la libertad, lo está volviendo responsable de sus actos, ahora el juego depende de él, está adquiriendo la posibilidad de elección existencialista. Ahora bien, si el mago representa a Allende, entonces, es éste quien le está dando la autorización a Castel para hacer su vida dependiendo de sus actos.

Allende, que es, de alguna forma, clarividente, ha percibido lo que está sucediendo y se está apartando del camino, de la responsabilidad. Ahora Castel, que está siendo libre, ejercita su libertad y se elige asesino. No haber sabido ser libre es lo que después Allende reprochará, puesto que no entendió lo que le había sido ofrecido, insensato. No obstante Castel, incluso en su reclusión, es libre, porque se eligió asesino, construyó su propio mundo.

\section{El mal como ascensión intelectual}

A primera vista, tanto El túnel como The Collector no parecen compartir mucho más que el desarrollo principal de su trama: ambas novelas exploran los límites de la obsesión de sus respectivos narradores, hasta el punto de causarle la muerte al objeto de dicha obsesión. Los detalles, personajes y estilos de las obras difieren de tal modo que una conexión más profunda podría ser fácilmente omitida por el lector. Juan Pablo Castel es un artista, perteneciente a un cierto gremio de intelectuales y miembros de la burguesía bonaerense. Su relación con María Iribarne es turbulenta pero, al menos en parte, correspondida. El crimen es un producto de su angustia enfermiza sobre la relación y de sus dudas existenciales. En The Collector, Frederick Clegg es un hombre reprimido, de clase trabajadora, cuya repentina fluidez económica representa su primer atisbo de libertad y poder en su vida. Una relación con Miranda Grey le parece tan improbable que su única alternativa es seguirla, raptarla y recluirla en su sótano para admirarla, como a una pieza en su colección de lepidópteros. La muerte de Miranda no es causada directamente por Clegg, sino por una neumonía que esta contrae durante su encierro.

Sin embargo, no es arriesgado afirmar que estas novelas contienen numerosos elementos comunes. Para esta disertación, la similitud más relevante es de carácter teleológico: ambos textos son claramente apologías del mal. Cada uno de los narradores es el causante, de forma más o menos directa, de la muerte de otro ser 
humano, y no de un ser humano cualquiera: se trata de la persona más importante en sus vidas. Escribir una versión de los hechos se hace necesario para los narradores, quienes, con métodos prácticamente opuestos, intentan justificar, e incluso elevar, dichas muertes. Tanto Castel como Clegg aprovechan el poder que tienen sobre la narración para presentarse de un modo específico, transformándose en personajes que podrían llegar a generar entendimiento e incluso simpatía por parte del lector.

Para lograr esto, cada protagonista asume una máscara que va a mantener a lo largo de la narración. Estas pueden ser diferentes entre sí, pero parecen ser igualmente eficaces. Castel decide usar su historia para construir un sistema filosófico prácticamente existencialista, cuya conclusión puede ser solo la soledad absoluta. En el caso de Clegg, este se muestra al lector como un hombre ingenuo pero bienintencionado, víctima de un sistema social clasista y dispuesto a amar ciegamente. El propósito de los siguientes párrafos es comparar dichas construcciones, y analizar como el discurso de cada narrador se desarrolla para defender su malignidad.

Ya en las primeras páginas de ambas novelas se puede entrever el trágico fin de las víctimas y, paralelamente, el método que cada uno de los narradores usará para convencer al lector de la aceptabilidad de sus respectivos crímenes. En El túnel, la máscara de Castel se hace evidente desde la primera oración, y consiste en la aparente ausencia de dicha máscara: "Bastará decir que soy Juan Pablo Castel, el pintor que mató a María Iribarne" (Sábato 1983: 9). Castel acepta su culpa abiertamente, lo cual deja en claro que el asesinato de María, más que el centro o la causa de su historia, es tan solo un pretexto para explicar los motivos que lo llevan a abrazar su maldad. El tono del primer capítulo es irreverente e impactante. Al escribir desde la cárcel, el pintor da la impresión de no tener nada que perder, lo cual contribuye a una sensación de honestidad visceral que se mantendrá a lo largo de la obra. Castel logra eliminar cualquier elemento de misterio de la perspectiva del lector y lo obliga a concentrarse en el análisis de sus motivos. Más que restarle importancia al asesinato de María, el narrador desea restarle importancia a la vida de la misma, y de consecuencia, a la vida humana:

¿Un individuo es pernicioso? Pues se lo liquida y se acabó. Eso es lo que yo llamo una buena acción. [...] En lo que a mí se refiere, debo confesar que ahora lamento no haber aprovechado el tiempo de mi libertad, liquidando a seis o siete tipos que conozco (Sábato 1983: 9-10).

El primer capítulo de El túnel funciona como la introducción a un texto científico, donde Castel expone su teoría sobre el mal como la mejor cualidad de la raza humana. El resto de la novela consistirá en una argumentación detallada de dicha teoría que, utilizando la historia de su crimen como ejemplo, pretenderá ser comprendida e incluso aceptada por el lector.

En el caso de The Collector, la apología del protagonista va a funcionar de una forma prácticamente contraria a la de Castel: Clegg aún no ha sido juzgado por su crimen, así que este no tiene motivos, a diferencia del pintor de Sábato, para mostrarse como culpable. Sin embargo, la exposición de esta obra también es indispensable para comprender la forma como el coleccionista va a intentar 
manipular a sus lectores. En las primeras líneas, la única alusión a lo ocurrido se presenta como un eufemismo escondido en una frase relativa, cuando describe a Miranda tan solo como una invitada en su casa (Fowles 2004: 9). Esta indiferencia a su crimen continuará dominando la novela: de hecho, solo en las últimas páginas de la obra se menciona directamente la muerte de la joven, y aun así, esta será tratada tan solo como una maniobra trágica del destino. Desde el inicio, Clegg quiere mostrarle al lector que no ve ninguna criminalidad en sus acciones, que él sería incapaz de hacerle daño a su amada, que su amor por ella es puro. No obstante, al lado de esta fascinación casi religiosa, no es difícil reconocer los signos de malignidad que acompañan a su obsesión. En las primeras páginas se narra también cómo Clegg comienza a seguir a Miranda, a obtener información sobre su identidad y rutina, y eventualmente cómo iniciará a conjurar su secuestro. Incluso se mencionan sueños de carácter sádico, en los que Miranda llora o se encuentra de rodillas, y Clegg la golpea, imitando a algún personaje de la televisión (Fowles 2004: 10-11). El truco de Clegg es maquillar su lado más siniestro, dándole un tono inocente y casi infantil a los aspectos más oscuros de sus acciones. Esta ingenuidad le proporciona la credibilidad que Castel obtiene con su honestidad visceral. El narrador va a mantener un tono que lo va a presentar como un hombre poco inteligente, si no enfermo, incapaz de distinguir entre el bien y el mal. No obstante, a lo largo de la narración, se hace cada vez más claro que Frederick Clegg es considerablemente más inteligente de lo que parece, y que su forma de mantener prisionera a Miranda es demasiado eficaz para no ser premeditada.

A partir de estos fundamentos, tanto Castel como Clegg van a desarrollar su versión de los hechos. Interesantemente, sus luchas personales parecen nacer de un elemento común: un agobiante sentimiento de alienación. Ambos narradores se declaran marginalizados, inconformes con un contexto social que los rodea y los limita.

Como se ha tratado en la sección anterior de este artículo, el lenguaje, o la deficiencia del mismo, juega un papel fundamental en el sentimiento de exclusión que domina la psicología de Castel. A su vez, la incapacidad de expresar lo que se desea expresar se manifiesta también en The Collector: por una parte se presenta a un Frederick Clegg que intenta escribir con un estilo refinado pero un tanto anacrónico y, a veces, incluso incorrecto. Más que mostrar la buena educación del narrador, su tono revela un intento fallido de escribir con literariedad, de convencer a su lector con una voz narrativa poderosa.

La similitud con El túnel se hace aún más clara en la segunda parte de la novela, el diario de Miranda, donde la joven misma alude al problema de escribir siendo su vocación las artes visuales.

What I write isn't natural. It's like two people trying to keep up a conversation. It's the very opposite of drawing. You draw a line and you know at once weather it's a good line or a bad line. But you write a line and it seems true and the you read it again later (Fowles 2004: 129).

De cualquier manera, el mal se presenta en las dos historias como el método más apropiado para lograr una especie de ruptura de esas barreras sociales y lingüísticas, lo cual representa un triunfo personal de los personajes. Para estos, 
superar su condición de marginados a través de sus crímenes constituye una ascensión casi mística.

En el caso de Juan Pablo Castel, su incomodidad con la sociedad parece tener un carácter principalmente intelectual: el narrador se declara incapaz de pertenecer a cualquier tipo de agrupación, sintiéndose avergonzado de su inferioridad económica (Sábato 1983: 19), pero sobretodo incomprendido por su sensibilidad artística superior. Como un pintor relativamente respetado, Castel siente que su vida es dominada por personas incapaces de entender su obra (Sábato 1983: 20). El pintor se ve atrapado en este círculo, un mundo de ignorancia y apariencias, donde las personas que deberían entenderlo -otros pintores o críticos- no parecen notar la angustia existencial que intenta plasmar en sus pinturas. La superficialidad de la relación es descrita simbólicamente a través de una de sus obras:

En el salón de Primavera de 1946 presenté un cuadro llamado Maternidad. Era por el estilo de muchos otros anteriores: como dicen los críticos en su insoportable dialecto, era sólido, estaba bien arquitecturado. Tenía, en fin, los atributos que esos charlatanes encontraban siempre en mis telas, incluyendo "cierta cosa profundamente intelectual". Pero arriba, a la izquierda, a través de una ventanita, se veía una escena pequeña y remota: una playa solitaria y una mujer que miraba el mar. Era una mujer que miraba el mar. Era una mujer que miraba como esperando algo, quizá algún llamado apagado y distante. La escena sugería, en mi opinión, una soledad ansiosa y absoluta (Sábato 1983: 14).

Es debido a dicha obra que el protagonista nota por primera vez a María: esta parece ser la única persona que nota la escena en la ventana, la única persona que oye el llamado de un artista sofocado por la intelectualidad de su arte. A partir de este momento, María se convierte en la obsesión de Castel, quien ve en la joven una forma de escapar de su soledad.

Sin embargo, a lo largo de la novela, más que aliviar las inseguridades de Castel, su romance con María las incrementa. El túnel se desarrolla como un estudio exageradamente racional, paródicamente científico, de la psicología del protagonista (Shaw 2014: 57), quien a su vez proyecta sus conclusiones a la psicología de su amada. Inicialmente, estas inseguridades se manifiestan a través de dudas sobre la fidelidad de la mujer. La relación de los personajes vaga constantemente entre la dependencia total y la agresividad sádica de Castel. $\mathrm{Su}$ comportamiento sexual y sus celos obsesivos se convierten en una representación simbólica de sus angustias metafísicas (Shaw 2014: 57). A medida que la historia se desarrolla, el narrador comprende que su relación con María no es una cura para su aislamiento; una vez satisfecho, es inevitable notar los defectos de su pareja, y por consiguiente sentirse decepcionado por la misma (Sábato 1983: 95). Con esta realización, sus angustias adquieren un carácter literal: sus procesos mentales parecen lógicos y comprensibles para el lector, quien es obligado a llegar a la conclusión de que María, como Castel, comprende y asimila lo absurdo y terrible de la existencia humana, y que por lo tanto no representa una salida de la soledad total. Esta revelación consagra al mal, que hasta ahora se había manifestado como un impulso irracional, como la única solución a los problemas del artista: 
¡Qué lástima que debajo hubiera hechos inexplicables y sospechosos! ¡Como deseaba equivocarme, como ansiaba que María no fuera más que ese momento! Pero era imposible: mientras oía los latidos de su corazón junto a mis oídos y mientras su mano acariciaba mis cabellos, sombríos pensamientos se movían en la oscuridad de mi cabeza, como en un sótano pantanoso; esperaban el momento de salir, chapoteando, gruñendo sordamente en el barro (Sábato 1983: 100-101).

Juan Pablo Castel logra trasmitir un mensaje claro al lector: María Iribarne es en efecto la persona que mejor lo entiende. Sin embargo, esto significa que la joven no representa su salvación, o que, mejor dicho, no existe tal salvación. Es en este punto cuando el narrador culmina y presenta su filosofía, de la cual, como explica Donald E. Shaw, proviene el título de la novela:

El túnel, oscuro y solitario, es la vida. A veces el amor ofrece la ilusión de que dos túneles, dos existencias se pueden unir; pero luego se advierte que el amor solo convierte el muro de piedra en un muro de vidrio, tras del cual la persona amada sigue separada para siempre por su esencial otredad (Shaw 2014: 57).

Para Castel, la única esperanza es separarse de esta ilusión radicalmente, lo cual puede darse únicamente con la eliminación de la persona amada. El asesinato de María es una rebelión contra una realidad absurda (Shaw 2014: 57). Ella se convierte en la proyección de la angustia del narrador, quien desea con ansias aceptar su propia existencia. Asesinar a su amada, a la mujer que lo comprende, cumple prácticamente una función de suicidio del Castel atormentado, y a su vez el renacimiento, gracias a la malignidad, de un Castel nihilista, que acepta e incluso celebra la tragedia de existir.

El narrador de El túnel, a pesar de escribir desde una prisión, ha alcanzado un estado de libertad inimaginable en su vida previa. Siendo un criminal, Castel ya no es juzgado por críticos ignorantes, su obra adquiere un valor que va más allá del arte. El pintor logra romper las barreras sociales que tanto despreciaba. Debido a la creación de su filosofía y a su nuevo entendimiento del mundo, el asesinato de María representa un triunfo intelectual del protagonista, quien finalmente encuentra, si no una explicación, un método para lidiar con su existencia.

En The Collector, como se ha mencionado anteriormente, Frederick Clegg también desea justificar su malignidad a través de una sensación de alienación, y de la necesidad de liberación de la misma. La represión de Clegg, más que ser intelectual, es de naturaleza social y sexual. La primera barrera con la que el protagonista se enfrenta es la división de clases característica de la sociedad británica. Clegg se muestra como un hombre simple, de la clase trabajadora, mientras que Miranda Grey es mostrada como el prototipo de una joven estudiante de la alta burguesía. Clegg desea presentar esta separación como algo congénito, fijado en su mente por siglos de estratificación. Tal sensación de inferioridad nata es esencial para su identidad.

$\mathrm{Su}$ alienación solo se ve confirmada cuando Clegg gana una suma considerable de dinero: su nueva fluidez económica, aunque le puede garantizar el poder sobre ciertos individuos, no lo convierte en un miembro de la clase alta: "everything in the room seemed to look down at us because we weren't brought up their way" 
(Fowles 2004: 14). La riqueza, además de resaltar su otredad, constituye el recurso literario perfecto para posibilitar la trama. El narrador elabora un meticuloso plan, que incluye la compra de una casa aislada y un vehículo, un viaje para su tía y prima por tiempo indefinido, además de todos los regalos imaginables para su futura invitada. De esta forma, su poder económico se convierte también en una herramienta para presumir de su generosidad hacia su familia y conocidos, lo cual contribuye a su imagen positiva en la percepción del lector (Fowles 2004: 13).

Durante el secuestro de Miranda, Clegg aún parece tener la esperanza de ganar su amor, mientras pasa suficiente tiempo con ella y le proporciona todo lo que desea. A través de sus diálogos, el coleccionista se muestra ante el lector como un hombre paciente y ciegamente enamorado. De forma paralela y sutil, se encarga también de revelar el comportamiento impulsivo e inmaduro de la joven, generando así una cierta antipatía hacia ella.

No obstante, incluso en caso de que Miranda llegara a simpatizar con su secuestrador, lo que hasta cierto punto parece ocurrir, existe una última barrera que podría explicar la naturaleza reprimida de Frederick Clegg. Con el objetivo de ganar su confianza e incrementar sus posibilidades de escape, en un momento de la novela Miranda se ofrece sexualmente a Clegg, revelando la probabilidad de que este sufra de impotencia. La cuestión no es admitida por el narrador, quien atribuye su fracaso amoroso a la vergüenza que sintió al descubrir la faceta más terrenal de su amada (Fowles 2004: 99). Sin embargo, a lo largo de la novela se presentan claros indicios del apetito sexual no consumado del hombre: al ganar el dinero, este acude a una prostituta, "to be able to know I'd had a woman" (Fowles 2004: 14); la acción tampoco es exitosa, aparentemente debido a sus propios nervios y al carácter bajo de la mujer (Fowles 2004: 14-15). Posteriormente, Clegg procede a comprar revistas pornográficas -"books of stark women" (Fowles 2004: 14)- e, incluso, a coleccionar fotografías de parejas teniendo relaciones sexuales en lugares públicos. Su voyerismo podría venir de la imposibilidad de consumar una relación por cuenta propia.

El tema tampoco es inusual en la obra de John Fowles: la energía sexual suele ser un símbolo de liberación personal, un antídoto a la represión (Sanders 1996: 617). En The Collector la imposibilidad de desatar dicha energía representaría por lo tanto la imposibilidad de Clegg de ser libre. Es acá cuando la duda sobre las buenas intenciones del protagonista es implantada tanto en el lector como en Miranda: si Clegg es impotente, su amor por Miranda pierde su carácter religioso. Se puede pensar que el secuestrador no abusa sexualmente de su rehén simplemente por el hecho de no poder hacerlo. Esta idea representa una amenaza clara a la máscara del narrador, y por esto decide no confesarlo en sus escritos.

Existe un último factor decisivo para la construcción de la apología maligna de Clegg. El lector tiene acceso al diario que Miranda escribe a través de su cautividad, presentado en su totalidad en la segunda parte de la novela. El diario muestra un desarrollo fascinante de la personalidad de la estudiante: esta pasa de ser un personaje caprichoso y poco agradable a sentir cierta comprensión y simpatía por su secuestrador. A su vez, los escritos revelan detalles de su vida social previa al secuestro, que dejan en claro que su presunta libertad es cuestionable: Miranda también se siente atrapada por su entorno y por su relación 
obsesiva y confusa con GP, su mentor intelectual y artístico, relación que adquiere claridad y madurez a lo largo del diario.

A diferencia de El túnel, donde es Juan Pablo Castel quien logra una transformación intelectual, en el caso de The Collector es la víctima quien realiza dicho proceso. Sin embargo, esto es precisamente lo que Clegg quiere demostrar: Miranda muere convertida en una mejor persona, y esto sucede gracias a la malignidad del secuestrador. Este reporta incluso que las últimas palabras de la muchacha son palabras de perdón (Fowles 2004: 266). Si la víctima misma, perteneciente a la clase superior, parece haber entendido y apreciado lo ocurrido, el lector se ve forzado a al menos considerar una justificación del crimen. Esta idea representa el triunfo definitivo del mal en The Collector. Clegg logra que Miranda consiga la libertad que nunca tuvo fuera del sótano, además de descubrir su propia vocación, su propia libertad. En las últimas páginas de la novela, el narrador confiesa haber encontrado una segunda mujer que despierta su interés $y$, manteniendo el mismo tono casual, sugiere que inicia la preparación de un nuevo secuestro (Fowles 2004: 282- 283).

Ahora se hace evidente que, a pesar de variar en temas, tono y estilo, tanto $E l$ túnel como The Collector constituyen historias donde la malignidad es el único método de ascensión intelectual, ya sea como víctima, como en la novela de Fowles, o como victimario, en el caso de El túnel. En ambas obras, las barreras y limitaciones de la condición humana solo pueden ser destruidas radicalmente, y el asesinato, el mal definitivo, se muestra como el método más apropiado para lograrlo. Tanto Sábato como Fowles juegan magistralmente con la idea del unreliable narrator: Juan Pablo Castel y Frederick Clegg usan su condición de narrador para defender este concepto ante un lector que, sin leer las obras atentamente, puede llegar a creer en sus testimonios, omitiendo el hecho de que provienen de un amante obsesivamente paranoico y de un potencial asesino en serie.

\section{Soy mirado luego existo}

Un masoquista le dice a un sádico: "Hazme sufrir". El sádico contesta: "No".

A lo largo del siguiente apartado se explorará el tipo de relaciones que se dan entre los protagonistas de la obra de teatro de Sartre titulada A puerta cerrada (1970). Tres personajes que se encuentran en el infierno y descubren lo que el estar allí realmente significa: el infierno son los otros. A partir de esta conclusión final del texto se pretende indagar acerca de la importancia de la mirada de los otros, pues parece ser que sin esa mirada no existimos y, sin embargo, no siempre es una mirada acertada porque el sujeto se percibe a sí mismo como un para-si en cambio la mirada externa lo contempla como un en-sí.

Bienvenidos al infierno. Los tres personajes de este infierno responden a los nombres de Garcin, Estelle e Inés, respectivamente y se comenzará con la confesión de lo que cada uno considera ser la razón de su llegada al infierno. Garcin torturaba a su mujer, hacía el amor con una mulata mientras su mujer 
escuchaba en el cuarto de arriba. Pero lo que a él realmente le preocupa es que fue fusilado por cobarde. Inés era lesbiana y sedujo a la mujer de su primo, quien muere en las rutas del tranvía, la mujer prende el gas y, finalmente, mueren las dos. Lo que acosa a Inés, realmente, es que es una antorcha en los corazones. Estelle, por su parte, mata a su hija recién nacida por odio contra el padre de la niña, éste se vuela la cabeza con un fusil. El hombre era su amante. Estelle está preocupada por gustarle a un hombre, cualquier hombre: por ser reconocida. Como puede verse se trata de personajes que son culpables por haber llevado la desgracia a otros, culpables por la relación que tuvieron con otros. No obstante, sus preocupaciones no tienen tanto que ver con su culpa, o arrepentimiento, como con una insatisfacción. En este infierno no parece que su capacidad de relación haya mejorado, aquí no habrá asesinatos, suicidios ni fusilamientos: ya están muertos. Tendrán que torturarse por el resto de la eternidad.

El cobarde: El afán de Garcin ahora, es no aparecer como un cobarde. Esto solo puede ser concebido en su para-sí, porque implica el deseo de cambio, de promesa, de proyectarse hacia el futuro. El hecho de su muerte apuesto el en-sí de manera permanente en su presente. Ahora, objetivado por la visión de Estelle y, sobre todo, por la de Inés, no puede cambiar, se ha convertido en objeto observado y estático. Es sobre todo Inés quién lo mirará de esta forma puesto que, como se verá más adelante, Estelle perderá voluntariamente la posición privilegiada de objetivar para convertirse en objeto. Retomando la situación de Garcin, puede notarse que hace un intento desesperado por recuperar su ser o, al menos, el conocimiento de ese ser. Las otras saben quién es el, son ellas quienes lo ven y, por tanto, lo definen. Garcin, en un intento de establecer la paz, podría incluso decirse que de aceptación de la muerte, propone que todos cierren los ojos y la boca. Al cerrar los ojos a los demás, él conseguiría escapar de la mirada que lo delimita y lo define, al cerrar la boca a los demás, él conseguiría que no le dijeran aquello que lo delimita y lo define. Esta sería la única manera de escapar de su en-sí; pero está en el infierno, no será posible.

El objeto: Estelle, por su parte, se abandona a la total objetivación de manera voluntaria. Con esto gana el automático reconocimiento por lo que es, por patético que se presente y aleja lo que fue. Niega su libertad, aunque carezca de ella y, al hacerlo, se convierte en objeto. Se entrega a los brazos, y a la voluntad, de Garcin, de manera total sin exigirle su libertad, sin siquiera buscarla. Es una actitud a todas luces masoquista. Esta actitud tiene al menos tres momentos claramente diferenciables. El primer paso es cuando se convierte en objeto para el mundo, en este punto puede ser objeto tanto para Garcin como para Inés y, en realidad, esta última se lamenta de la presencia de Garcin, pues de no estar allí está segura de que podría apropiarse de Estelle. La mirada de Garcin es importante puesto que Estelle quiere escudarse en un hombre que, como se ha dicho, puede ser cualquiera. Pero es allí en donde radica la verdad de la frase Inés y, esto es, que puede ser cualquier hombre en la medida en que sea reconocida por alguien y, a falta de un hombre, la mujer servirá el mismo propósito (Sartre 1970: 152). En un segundo momento, ya establecidos los límites de la objetivación, es rechazada por Garcin. Ella le dice que se entregará a él sin importar si es un cobarde o no, y esto es inaceptable para Garcin. Él no quiere que no importe, él quiere demostrar que no es un cobarde, por lo tanto es inaceptable que Estelle no le dé importancia a este hecho. Es inaceptable 
en la medida en que la mirada de Estelle es tan real como la de un oso de peluche, esto es, con apariencia de un ser que mira, pero con mirada vacía, esto es, una mirada inexistente. Sin esa mirada Esther tiene la relevancia de un electrodoméstico, de un objeto cotidiano, presente pero inexpresivo, incluso sin amago de mirada. Nada aporta a la definición de Garcín. Sin embargo, en un tercer momento, Garcin sucumbe al acoso de Estelle en una búsqueda desesperada por aprehender la mirada que ella tiene de él y, en esa medida, completarse; encontrarse. Quiere ser fundamento y fundado; al conocer lo que ella sabe de él, vencer a la muerte. No es posible.

No es posible por al menos dos razones. En primer lugar si la relación se diera en el nivel inmediato de los acontecimientos de la obra, se asistiría al fracaso inminente de una relación de masoquismo.

El masoquismo es y debe ser en sí mismo un fracaso: para hacerme fascinar por mi yo-objeto, sería menester, efectivamente, que pudiera realizar la aprehensión de este objeto tal cual es para el otro, lo cual en principio es imposible. Así, el yo alienado, lejos de poder yo ni siquiera empezar a fascinarme con él, permanece por principio incaptable (Sartre 1998: 472).

Es el otro quien determinará, evaluará y juzgará las conductas del masoquista y, en esta objetivación, el masoquista pierde toda posibilidad de hacerse notar realmente, en su subjetividad, puesto que la ha rechazado y es por eso que su mirada no aporta pues no es mirada de sujeto, de subjetividad, sino de objeto. Con esa mirada el otro no puede complementarse, no puede conocer de sí lo que quiere saber y, por lo tanto, a menos que adopte actitud de sadismo, que no se da, en el caso de Garcin, no estará interesado en la relación.

En segundo lugar, suponiendo que la relación entre los dos avanzara hacia los terrenos del amor, hace su aparición la tercera destrucción del amor que comenta Sartre y que se encargaría de hacer fracasar la relación. Esta destrucción consiste en la objetivación de la pareja por parte que terceros. (Sartre 1998: 470) La mirada de un tercero no solo objetiva a la pareja sino que, a la vez que hace a cada uno consciente de que esta objetivación, es consciente de la del otro, en esa medida el otro se convierte en objeto, asemejándose a una doble relación masoquista, lo cual por principio es imposible. El tercero, en este caso, sería Inés.

El dios muerto: ¿Por qué Garcin no busca el reconocimiento de su inexistente para-sí en Inés? ¿Por qué Estelle no busca el reconocimiento o su objetivación en Inés? Tal vez porque Inés es diferente, Inés actúa de manera impecable con el verdadero otro. La gran mirada omnisciente, la total mirada subjetiva imposible de objetivar. Podría pensarse que esta condición la pone en una posición privilegiada, o le da alguna ventaja, sin embargo, no es así en absoluto. Inés se elige libre para mirar al otro, deliberadamente mira la mirada del otro, al hacer esto se sitúa en su propia libertad y afronta la libertad tanto de Garcin como la de Estelle. Al hacer esto, confronta las dos libertades, la propia y la del otro. El resultado es que termina por objetivizar al otro, esto es, le aniquila su libertad. Con esto logra desaparecer la mirada de los otros, los convierte, de nuevo, en osos de peluche. Pero esto le previene de interactuar con ellos más de lo que podría hacerlo con un electrodoméstico. Esta actitud, que Sartre denomina como indiferencia hacia el 
prójimo, es, en sí misma, otro fracaso. Es la negación misma de la relación. Pero entonces podría pensarse, por un instante, que al no existir realmente la mirada de los otros, por vía de aniquilamiento, Inés es libre. Antes de determinar la posibilidad de esta afirmación, es preciso resolver las preguntas que abren el párrafo.

Garcin no puede buscar su fundamento en Inés porque ella, con su mirada totalizadora, ha fijado el en-sí de Garcin para toda la eternidad. Lo enfrenta a la ausencia de un para-sí y, al aniquilar la mirada, incluso la mirada sobre sí mismo, no le permite proyectar absolutamente nada; lo priva de futuro y en esa medida lo convierte en cobarde, lo que para él es insoportable. Por otra parte, Estelle no puede buscar el reconocimiento de Inés porque la relación de indiferencia la priva hasta de la posibilidad de ser masoquista y objeto. El objeto no le dice nada a Inés. Falta encontrar el castigo de Inés.

Inés.- Yo sí, yo soy mala; eso quiere decir que necesito el sufrimiento de los demás para existir. Soy como una antorcha: una antorcha en los corazones. En cuanto estoy sola me apago. Durante seis meses estuve ardiendo en su corazón; y lo quemé todo (Sartre 1974: 156).

Inés no puede vivir sin los otros, pero al aniquilarles la mirada y convertirlos en mirados, los pierde. Los pierde para siempre, es un constante morir y, ahora que ha muerto, recuérdese la pregunta acerca de su libertad: ¿es libre? Podría serlo, tal vez, desde el punto de vista de una situación con futuro variable, esto es, con la posibilidad de un futuro con cambios, con opciones, con alternativas o consecuencias. El futuro de la obra es solo futuro en un sentido ficticio, ha sido necesario para dar espacio a la linealidad de las palabras, al discurso, pero las cosas nunca van a cambiar en el infierno. El tiempo que discurre por la obra es solo una ilusión pues en la eternidad no hay tiempo. Teniendo en cuenta que la libertad es una elección auténtica en presencia de la muerte entonces no puede afirmarse nada con respecto de la libertad de Inés porque está muerta. La libertad en su definición incluye la existencia de un para-sí. Inés carece de uno.

No puede dejarse por fuera, en el capítulo acerca de la mirada, la mención a la ausencia de espejos en la obra. Es indispensable que no haya espejos puesto que el espejo sería una metáfora de la mirada de algún personaje a sí mismo. Para que el infierno sean, verdaderamente, los otros, solo ellos nos pueden mirar. Es necesario, indispensable, el solipsismo, en donde el ojo puede ver todo menos al ojo mismo. Un espejo destruye la dependencia absoluta en la mirada de los otros puesto que la mirada del sujeto sobre sí mismo es aseguradora. La metáfora conduce a plantear la ignorancia de cómo es uno realmente. La carencia de esta información nos obliga a confiar en los demás en busca de nosotros mismos. Recordando la escena en donde Inés le propone a Estelle el que se mire en sus ojos para buscar el reflejo, y así descubrirse, es exactamente la catalización de la metáfora: no hay mirada propia, no hay salida, soy lo que los demás ven de mí. 


\section{Las libertades subterráneas}

Como se ha intentado demostrar anteriormente, la influencia de la filosofía de Sarte en El túnel es evidente; tanto conceptualmente, como a través de referencias literarias más o menos directas, ofrecidas por el mismo autor. Teniendo presente los desarrollos similares de la novela de Sábato y de The Collector también resulta necesario apreciar la segunda dentro de un marco filosófico existencialista. Al igual que en la historia de Juan Pablo Castel, la de Clegg consiste básicamente en un intento de construcción de su libertad, un desprendimiento paulatino de su mala fe: el proceso inicia involuntariamente, catalizado por el dinero, pero eventualmente se completa con el secuestro de Miranda y los sucesos que lo siguen. Frederick Clegg toma sus decisiones y sigue su voluntad ignorando cualquier barrera social o moral. Es así como el coleccionista descubre la expresión más extrema de su afición, convirtiéndose potencialmente en un asesino en serie. Sus decisiones involucran la negación de la libertad e incluso de la vida de otros, pero esto no representa un obstáculo para el personaje. A primera vista The Collector parece ser una novela donde el villano triunfa, incluso desde un punto de vista sartriano. Sin embargo, esta victoria no es definitiva: la libertad de Clegg es de hecho bastante frágil, ya que se basa en factores externos a su forma de pensar: las acciones que constituyen su libertad son posibles solo gracias a su situación económica privilegiada y al hecho de que su crimen no es descubierto, al menos hasta el punto en el que termina la narración. Pero sobre todo, el sentido de su vida yace en su dependencia a Miranda, o por lo tanto a cualquier otra mujer que actúe como su sucesora. Esta obsesión podría considerarse como otra forma más de autoengaño, un ejemplo claro de mala fe.

Más que alejarnos del desarrollo existencialista de la novela, este hecho solo lo confirmaría. En efecto, The Collector presenta constructos similares a los que Sartre mismo establece en su obra filosófica y literaria. La obsesión de Clegg con su cautiva es mostrada prácticamente como un arquetipo extremo de una relación masoquista. A lo largo de la novela se hace cada vez más claro que la libertad de Clegg y la cautividad de Miranda se limitan a un contexto literal. Es Miranda quien parece tener el poder sobre la relación, mientras que el poder del coleccionista se limita al acto físico de tenerla prisionera. La dinámica entre los personajes se hace especialmente clara en los episodios en los que Miranda ataca psicológica, o incluso físicamente a su secuestrador, ya sea como una estrategia para escapar, o como un gesto de desesperación ante su situación. Las agresiones verbales de la joven consisten usualmente en resaltar la inferioridad Clegg: "I always seem to end up by talking down to you. I hate it. It's you. You always squirm one step lower than I can go" (Fowles 2004: 76). Miranda insiste en dejar claro que Clegg no es más que un Caliban, un ser bajo y ordinario. Esta es precisamente la mayor angustia del protagonista, quien ve en esta inferioridad una confirmación de la imposibilidad de establecer una relación ulterior a la que se establece entre secuestrador y secuestrado. No obstante, esta idea no mitiga su fascinación por la muchacha. Incluso luego del episodio más crítico, en el cual Miranda ataca en vano a Clegg con un fuerte golpe a la cabeza, es ella quien tiene el control total de la situación, limpiando su herida y reestableciendo una relación cordial. La reacción de Clegg ante lo sucedido deja poco más que explicar: 
It was all formal, she turned away to have her breakfast, and I waited outside. When I knocked on the door to see if I could clear away [...] I asked if she wanted anything but she didn't. She said I was to get TCP ointment for myself, and she handed me the tray with just the ghost of a smile. It doesn't seem much, but it marked a big change. It almost seemed to make the head worth it. I was really happy that morning. Like the sun was coming out again. (Fowles 2004:93)

Fuera de contexto, la cita hace pensar que ha sido Clegg quien ha cometido la agresión y necesitase el perdón de su prisionera. El protagonista se comporta y piensa casi como un sirviente de Miranda. Las situaciones de masoquismo son recurrentes en la narración, y sin embargo el hombre describe esos días como lo más felices de su vida (Fowles 2004:11). Como en A puerta cerrada, el infierno de Clegg, el máximo obstáculo de su libertad, no es más que otra persona.

Igual o aún más interesante es analizar la situación de Miranda, lo cual es facilitado por la presencia de su diario en la novela. En cierto sentido se podría afirmar que Miranda inicia su narración en una situación similar al final de $A$ puerta cerrada, aunque tal vez no tan certera: "Last night, I thought - I am dead. This is death. This is hell. There wouldn't be other people in hell. Or just one, like him." (Fowles 2004: 124). Como se intentó mostrar en la cuarta parte de este estudio, Miranda es el personaje que logra una especie de desarrollo intelectual a medida que la novela progresa. Durante su cautiverio, la joven reflexiona constantemente sobre la vida que llevaba fuera del sótano de Clegg, reparando muchos de sus defectos de carácter, y eventualmente consiguiendo una claridad y una madurez que tal vez no hubiera obtenido de no haber sido raptada. A falta de una libertad literal, la construcción de libertad de Miranda se basa es sus esperanzas y realizaciones respecto al mundo exterior, y en especial alrededor de su relación con GP, por quien descubre una inclinación amorosa que antes se había presentado como una admiración intelectual confusa.

No obstante, su libertad solo puede ser construida en su imaginación. Miranda sigue prisionera en un sótano, y las dudas sobre la posibilidad de salir con vida de la situación incrementan proporcionalmente a su sabiduría y su libertad teórica. E incluso, su confinamiento no resulta ser lo peor: desde un punto de vista sartriano, el nuevo entendimiento de Miranda no equivale a libertad, ni siquiera en su imaginación. Sus sentimientos hacia GP, aunque representen claridad ante la confusión existencial de la muchacha, no son más que otra confirmación del carácter sádico/masoquista que Sartre encuentra en cada relación. La joven es consciente del carácter poco saludable de una potencial relación con su mentor:

I know I can't do things like love by halves, I know I have love pent up in me, I shall throw myself away, lose my heart and my body and my mind and soul to some cad like GP. Who'll betray me. I feel it. Everything is tender and rational at first in my daydreams of living with him, but I know it wouldn't be in fact. It would be al passion and violence. Jealousy. Despair. Sour. Something would be killed in me. He would be hurt, too. (Fowles 2004: 235) 
Incluso en sus sueños la felicidad de Miranda se muestra imposible. Lo más cercano a la libertad que la joven puede obtener es la certeza de que no existe dicha libertad, ni en la casa de Clegg ni en el mundo exterior que debería proporcionársela. La nueva sabiduría de Miranda representa la eliminación del autoengaño. Miranda logra superar su mala fe y sin embargo es prisionera, tanto de Clegg como de GP. Al igual que su secuestrador, y que los personajes de $A$ puerta cerrada, Miranda llega a la conclusión de que el infierno no es un concepto espacial: su infierno no es el sótano, ni el mundo exterior, sino su permanente dependencia, voluntaria e involuntaria, a otros seres humanos.

Sin embargo, durante sus últimos días, la voluntad de vivir de Miranda parece incrementar, y la aparición de su enfermedad solo le provoca una agonía mayor a la sentida anteriormente (Fowles 2004: 259). Miranda está dispuesta a utilizar su intelecto, a iniciar una nueva construcción de su libertad. Su reclusión y las bajas expectativas sobre su futuro no son suficientes para apaciguar su necesidad de poner en práctica lo aprendido durante el cautiverio. Ante esta epifanía inútil es el destino quien debe encargarse de negar sus deseos, y así culminar forzosamente su desengaño. La enfermedad y muerte de Miranda podrían adquirir entonces un nuevo carácter simbólico, la única respuesta sensata a las angustias de la joven; como para Castel en El túnel, la muerte es la máxima negación de sus esperanzas ilusorias, y tal vez un último intento de conseguir algo cercano a la libertad.

\section{Referencias bibliográficas}

Borges, Jorge Luis, "La casa de Asteríon”, en El Aleph. Buenos Aires: Emecé, 1957.

- "La muerte y la brújula", en Ficciones. Obras Completas I. Barcelona: Emecé, 1996.

- "Funes, el memorioso", en Ficciones. Obras Completas I. Barcelona: Emecé, 1996.

Boscán de Lombardi, Lilia. Aproximaciones críticas a la narrativa de Ernesto Sábato. Maracaibo: Editorial Maracaibo, 1978.

Carroll, Lewis. Alice in Wonderland \& Through the Looking Glass. New York: Grosset \& Dunlap, 1992.

Conradi, Peter. John Fowles. Londres: Methuen \& Company, 1982.

Eco, Umberto. Interpretación y sobreinterpretación. Melbourne: Cambridge University Press, 1992.

Esquilo. La orestíada. Barcelona: Juventud, 1980.

Fowles, John. The Collector. Londres: Vintage, 2004.

Huffaker, Robert. John Fowles. Boston: Twayne Publisher, 1980.

Locke, John. Ensayo sobre el entendimiento humano. Buenos Aires: Aguilar.

Olshen, Barry N. John Fowles. New York: Frederick Ungar Publishing, 1978.

Perse, Saint-John. Pájaros. Bogotá: Escala, 1985.

Petrea, Mariana D. Ernesto Sábato: la nada y la metafisica de la esperanza. Madrid: Porrúa, 1986.

Sábato, Ernesto. El túnel. Barcelona: Seix Barral, 1983.

Sanders, Andrew. The Short Oxford History Of English Literature. New York: Oxford University Press, 1996.

Sartre, Jean Paul. A puerta cerrada en Obras completas. Tomo I. Madrid: Aguilar, 1974.

- Las moscas en Obras completas. Tomo I. Madrid: Aguilar, 1974.

- El ser y la nada. Buenos Aires: Losada, 1998.

-El existencialismo es un humanismo. Barcelona: Edhasa, 1999. 
Shaw, Donald L. Nueva narrativa hispanoamericana. Boom. Posboom. Posmodernismo. Madrid: Cátedra, 2014.

Swift, Johnatan. Gulliver's Travels. London: Penguin, 1994. 